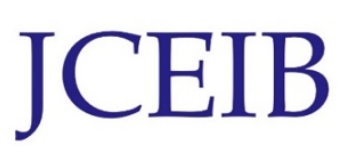

Open Access; Volume 1 pp. 72-82; March2017

(C)Universiti Malaysia Pahang Publisher

DOI: https://doi.org/10.15282/JCEIB-V1-12.31/3/2017/1.1.1

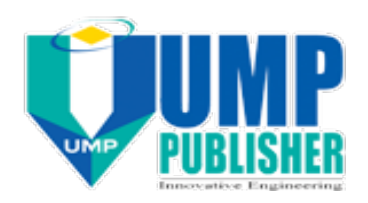

\title{
OPTIMIZATION ON DYEING UPTAKE EXHAUSTION PERCENTAGE OF BETACYANIN PIGMENT EXTRACTED FROM HYLOCEREUS POLYRHIZUS PEEL ONTO THE SPUN SILK YARN USING CENTRAL COMPOSITE DESIGN
}

\author{
Norasiha Hamid $^{\mathrm{a}}$, Mimi Sakinah Abdul Munaim ${ }^{\mathrm{a}^{*}}$ \\ ${ }^{a}$ Faculty of Engineering Technology, Universiti Malaysia Pahang, 26300, \\ Kuantan, Pahang \\ Corresponding author: E-mail: mimi@ump.edu.my \\ Tel.: +609-5493191 Fax.: +609-5493190
}

\begin{abstract}
The prior motivation of this research study is to determine the ideal condition for dyeing process of spun silk yarn with natural dye extracted from dragon fruit peel using a central composite design. The peel of dragon fruit is contained betacyanin pigment can be utilized to be a natural dye which normally the peel of dragon fruit was discarded as a waste. As the betacyanin pigment was considered to be a newest red dye color in textile application, it is necessary to determine the optimal value for its specific dyeing process. In this experiment, natural dye was extracted from dragon fruit peel using water extraction with the acidified water as a medium. The natural dye was then applied onto the spun silk yarn at different dyeing time $(60-90 \mathrm{~min}), \mathrm{pH}(3-5)$ and dye concentration $(100-120$ $\mathrm{g} / \mathrm{L})$. The dye-uptake of natural dye was measured using UV-Vis spectrophotometer. The result of dye-uptake percentage was employed using analysis of variance (ANOVA). By ANOVA, the dyeing condition was determined as $\mathrm{pH}$ of 2, dyeing time of $95 \mathrm{~min}$ and the dye concentration of $110 \mathrm{~g} / \mathrm{L}$ which is generated from the mathematical model. Using the ideal condition, the dye uptake percentage was determined to be $51.58 \%$ to a desirability value of 0.995 . So, it is concluded that dyeing condition for the optimal value of dyeing uptake exhaustion of betacyanin pigment onto the spun silk can be determined using CCD.
\end{abstract}

Keywords: natural dye, exhaustion, central composite design, spun silk dyeing, betacyanin extract

\subsection{INTRODUCTION}

Nowadays, the demand for natural colorants is growing worldwide because they are more eco-friendly and non toxic compared to synthetic colorants (Guesmi et al., 2012). The use of the natural dye/ colorant has numerous advantages including high bio-degradability and compatibility with the environment (Erkan et al., 2011). A red-violet color of dragon fruit peel is contributed from the betacyanin pigment (Kunnika and Prancee, 2011). Betacyanin pigment extracted from the various plants has been reported to be used as a natural colorant in a food and cosmetic industry (Britton et al., 2002). Yet, there is no 
such application in the textile industry. So, it is suggested to apply the betacyanin pigment extracted from dragon fruit peel in a usage of dyeing textile application. Dragon fruit (Hylocereus spp.) is a one of the cactus fruit from the Cactaceae family which has been commercially cultivated in tropical climate especially in Malaysia. Dragon fruit is rich with the nutrients, minerals and furthermore abundantly antioxidant properties (Zainoldin et al., 2009). The peel from the dragon fruit is usually discarded by the food manufacturing industries and end up as a waste. The peel of dragon fruit can be exploited by extracting its vibrant color to be a natural dye as an alternative to replace the synthetic dye, especially in textile application. In modern textile dye houses, the insertion of natural dyes necessitates the classifications of products in terms of standardized quality including the shade of dyeing, the depth of the color and also natural properties (Nasirizadeh et al., 2012).

Optimization of dyeing is definitely the substantial method to determine the optimum condition in order to get highest dyeing uptake exhaustion. As the betacyanin pigment extracted from the dragon fruit peel had never been used in the textile application, it is necessary to study the significant variables with the certain conditions that affect the dyeing exhaustion. Response surface methodology (RSM) is one of a perfect method to simulate the variables simultaneously (Karthikeyan et al., 2010). It additionally can decide ideal restrictive for multi parameters and the interactives impacts. Thus, it has widely used in process and product improvement because it can optimize the complex process and minimixe the experimental numbers of trials (Sinha et al., 2012). The key purpose of this study is to optimize the dyeing conditions between betacyanin pigments extracted from dragon fruit peel onto of the spun silk yarn. The significant factors such as dyeing time, dye-bath concentration and $\mathrm{pH}$ of the solution have been identified and proceed further using central composite design (CCD) under RSM. The CCD is perceived the association among the parameters utilizing the generated statistical models (Demirel and Kayan, 2012). In the last part of the CCD, the optimal conditions were determined to achieve the maximum dyeing uptake percentage during the dyeing process.

\section{Spun Silk Preparation}

\subsection{EXPERIMENTAL METHODS}

The spun silk yarn at about $100 \mathrm{~g}$ was soaked in boiling water of $2 \mathrm{~L}$ for about $1 \mathrm{hr}$, in the purposed of eliminating the dirt and dust. After that, the spun silk was removed and rinsed with the cold water. The excess water was squeezed and lastly, dried in the air (Chairatanaphani, 2008). The dried spun silk yarn was then weighted at about $1 \mathrm{~g}$ to use in the experiment.

\section{Betacyanin Extraction}

The raw material, dragon fruit was purchased from the regional cultivator near to Gambang, Pahang and kept at $4{ }^{\circ} \mathrm{C}$ before proceed for the extraction process. The peel was separated manually from the fruit and washed thoroughly. The peel was then cut into a small pieces at about $1 \mathrm{~mm}$ and macerated by using a blender (Guesmi et al., 2013). The macerated juice was subjected to the dye extraction. The extraction was carried out by applying the solid to liquid ratio (SLR) of 1:5 equivalents to $10 \mathrm{~g}$ of macerated juice into $50 \mathrm{~mL}$ of water in the water-bath shaker for 30 minutes in the temperature of $45^{\circ} \mathrm{C}$. 
The dye solution was detached from the plant tissue with the help of a Buchner funnel lined with the filter paper, linked to the vacuum pump (Tang \& Norziah, 2007). To make sure the dye solution is clear from the plant tissue, the filtered solution was centrifuged for 15 minutes at the speed of $9000 \mathrm{rpm}$. The extracted solution was kept in the dark brown storage box for the next experiments.

\section{Instruments}

The absorbance measurements were recorded using UV-Visible spectrophotometer by using quartz cells of path length $1 \mathrm{~cm}$. The dye uptake percentage was measured using the absorbance of dye solution before and after dyeing in three measurements. The adsorbance was measured at maximum wavelength which is $538 \mathrm{~nm}$.

The percentage of dye uptake exhaustion was calculated (Nasirizadeh et al., 2012) by using the relation given in Equation 1:

$$
E \%=(\text { Abs }(\text { before })-\text { Abs }(\text { after }) / \text { Abs (before })) \times 100
$$

For $\mathrm{pH}$ measurement of the betacyanin solution, a pH meter (Mettler Delta 320) was used.

\section{Experimental Design}

The RSM method was used to determine the optimum conditions for a multi-variable system and to anticipate the collective influence of few variables. The CCD under RSM was utilized to improve the screened medium components that influencing the dye exhaustion. The CCD was used to examine the importance effects of $\mathrm{pH}$, dyeing time and dye-bath concentration. The software Design Expert was used to the model the experimental data obtained from a laboratory-scale setup. The optimization process using CCD was involved 17 runs with three-factor of five levels. Three of the screened factors from the factorial analysis process were used as the independent factors. The three factors were further optimized namely dyeing time, dye-bath concentration and $\mathrm{pH}$. In this design, the temperature and salt concentration were maintained at $45^{\circ} \mathrm{C}$ and $0.3 \mathrm{~g} / \mathrm{L}$, respectively, due to its lower significance for dyeing uptake exhaustion. the range for the significant factor are stated as following; the dyeing time represented as ' $A$ ' ranged from $80 \mathrm{~min}$ to $100 \mathrm{~min}$, followed by dye-bath concentration represented as ' $\mathrm{B}$ ', which ranged from $80 \mathrm{~g} / \mathrm{L}$ to $120 \mathrm{~g} / \mathrm{L}$ and the $\mathrm{pH}$ represented as ' $\mathrm{C}$ ' ranged between 1 to 5 . The ranges of independent variables are summarized in Table 1. An analysis of variance (ANOVA) and $R^{2}$ (coefficient of determination) statistical methods were implemented to confirm the adequacy of the developed model (Subroto et al., 2015). 
Table 1: Independent variables and concentration levels for response surface study

\begin{tabular}{|c|c|c|c|c|c|c|}
\hline \multirow[t]{2}{*}{ Factors } & \multirow[t]{2}{*}{ Unit } & \multicolumn{5}{|c|}{ Levels } \\
\hline & & -2 & -1 & 0 & 1 & 2 \\
\hline A $\left(x_{1}\right)$ dyeing time & Minute & 80 & 85 & 90 & 95 & 100 \\
\hline B $\left(x_{2}\right)$ dye concentration & $\mathrm{g} / \mathrm{L}$ & 80 & 90 & 100 & 110 & 120 \\
\hline $\mathrm{C}\left(\mathrm{x}_{3}\right) \mathbf{p H}$ & $\mathrm{pH}$ & 1 & 2 & 3 & 4 & 5 \\
\hline
\end{tabular}

\section{Verification of Optimized Conditions and Predictive Models}

The verification step is comparing the value from the experiment with the predicted values under the optimal conditions (Prakash et al., 2012). The proposed dyeing conditions were 95 minutes for dyeing time, the dye concentration of $110 \mathrm{~g} / \mathrm{L}$ and the $\mathrm{pH}$ of 2 . The residual and percentage error from both actual and predicted values were calculated using Equation 2 and Equation 3 respectively, as given below:

$$
\begin{aligned}
& \text { Residual }=(\text { actual value }- \text { predicted value }) \\
& \text { Error \% }=(\text { Residual } / \text { actual value }) \times 100
\end{aligned}
$$

\subsection{RESULTS AND DISCUSSIONS}

\section{Fitting of Second Order Polynomial Equations and Statistical Analysis}

The quadratic model was found statistically substantial to signify the dye uptake exhaustion percentage response, as shown in the Fit summary of output analysis. The adequacy of the quadratic model was examined by F-test, "Prob $>$ F" values and the determination coefficient $\mathrm{R}^{2}$. The generated $\mathrm{F}$ and Prob $>\mathrm{F}$ are recorded in Table 2 . The model was highly significant because the F value is 422.37 and the Prob $>F$ is indicating less than 0.0001 as observed in Table 2. The values of "probability more than F" for the terms of the model under 0.05 (95\% confidence level) determine that the generated model is recognized to be statistically significant at $95 \%$ confidence level which is required. It reveals that the terms of the model have significance over the response (Ojha and Achwal, 2014). Similarly, the correlation coefficient $R^{2}$ was calculated to be 0.9987 . Also, an acceptable agreement with the adjusted determination coefficient is essential. The $A d j-R^{2}$ value of 0.9963 was found in this research study. The values of $R^{2}$ and $A d j-R^{2}$ are close to 1.0 signifying a high correlation between the experimental and predicted values. Furthermore, the value of 'Lack of fit' turned out insignificant (Prob $>F=0.7720$ ) indicating an acceptably fit model. Moreover, as shown in Table 2, the primary impact towards the rate of dyeing uptake are dyeing time (A) and $\mathrm{pH}(\mathrm{C})$ were emerged to be the most substantial factors. Followed by the second order effect of dyeing concentration $\left(\mathrm{B}^{2}\right), \mathrm{pH}\left(\mathrm{C}^{2}\right)$ and dyeing time $\left(\mathrm{A}^{2}\right)$ and the two-level interactions between dyeing time and $\mathrm{pH}(\mathrm{AC})$. Furthermore, the primary influence of dyeing concentration (B), the twolevel interaction between dyeing time and dye concentration $(\mathrm{AB})$ and two-level interaction between dyeing time and $\mathrm{pH}(\mathrm{BC})$ were found to be corresponding to the secondary effect on the dyeing uptake percentage. 
With the assistance of the responses for the relating coded estimation of the three distinctive process factors, the polynomial regression modelling was executed, and the outcomes were evaluated. The subsequent equation was employed to obtain the predicted response (Y) for the percent of dye uptake exhaustion:

Final empirical model in terms of coded factors as given in Equation 2:

$$
\begin{gathered}
\text { Dye uptake }(\%)=47.60^{*} A-12.10^{*} B+4.24^{*} C-4.17^{*} A^{2}-3.29^{*} B^{2}- \\
2.23^{*} A^{*} B-1.28^{*} A^{*} C+0.034^{*} B^{*} C
\end{gathered}
$$

Final empirical model in terms of actual factors

Dye uptake $(\%)=$

- 1725.54 + 30. 48*dyebath concentration $+112.18^{*} p H+15.98^{*}$ dyeing time

- $0.17^{*}(\text { dyebath concentration })^{2}-13.14^{*}(p H)^{2}-0.092^{*}(\text { dyeing time })^{2}-$

$0.89 *$ (dyebath concentration*dyeing time $)+0.013^{*}\left(p H^{*}\right.$ dyeing time $)$

The empirical model equation is the mathematical correlation model that could be used in the optimization and prediction of the dyeing uptake percentage within the range of variable factors in this experiment.

Table 2: ANOVA analysis and statistical parameters of the model

\begin{tabular}{lllllll}
\hline Source & $\begin{array}{l}\text { Sum of } \\
\text { squares }\end{array}$ & DF & $\begin{array}{l}\text { Mean } \\
\text { squares }\end{array}$ & F-value & Prob $>$ F & \\
\hline Model & 5103.21 & 9 & 567.01 & 422.37 & $<0.0001$ & Significant \\
$\mathbf{A}$ & 33.64 & 1 & 33.64 & 25.06 & 0.0041 & \\
$\mathbf{B}$ & 0.78 & 1 & 0.78 & 0.58 & 0.4794 & \\
$\mathbf{C}$ & 2772.89 & 1 & 2772.89 & 2065.49 & $<0.0001$ & \\
$\mathbf{A}^{\mathbf{2}}$ & 17.33 & 1 & 17.33 & 12.91 & 0.0157 & \\
$\mathbf{B}^{2}$ & 1259.71 & 1 & 1259.71 & 938.34 & $<0.0001$ & \\
$\mathbf{C}^{\mathbf{2}}$ & 1053.94 & 1 & 1053.94 & 785.06 & $<0.0001$ & \\
$\mathbf{A B}$ & 2.10 & 1 & 2.10 & 1.57 & 0.2663 & \\
AC & 3.62 & 1 & 3.62 & 2.70 & 0.1616 & \\
$\mathbf{B C}$ & 1.81 & 1 & 1.81 & 1.34 & 0.2986 & \\
Residual & 6.71 & 5 & 1.34 & & & \\
Lack of Fit & 2.51 & 3 & 0.84 & 0.40 & 0.7720 & Not \\
& & & & & & significant \\
\hline
\end{tabular}

\section{Adequacy of the Models}

Figure 1 (a) shows a normal probability plot of the residuals, which demonstrates the residual distribution was closely to a straight line. The straight line implies the even distribution of errors and the adequacy of the least square fit (Zularism et al., 2009). The data points also indicate that the normality is normal and the responses change is unnecessary. Figure 1 (b) is a plot of residuals against the predicted response of dyeing uptake rate which demonstrates that the proposed models is certainly satisfactory. As studentized residuals are equally tabulated within the red line along the $\mathrm{x}$-axis, it means that the data is free from any desecration of the independence or constancy variance 
assumption. Thus, the model is sufficiently to be utilized as a part of upgrading the dyeing condition for betacyanin pigment onto the spun silk.

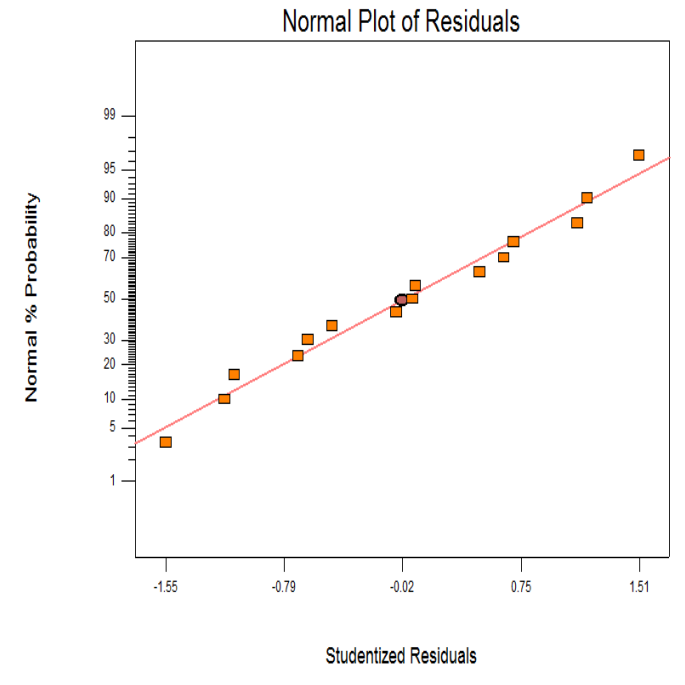

(a)

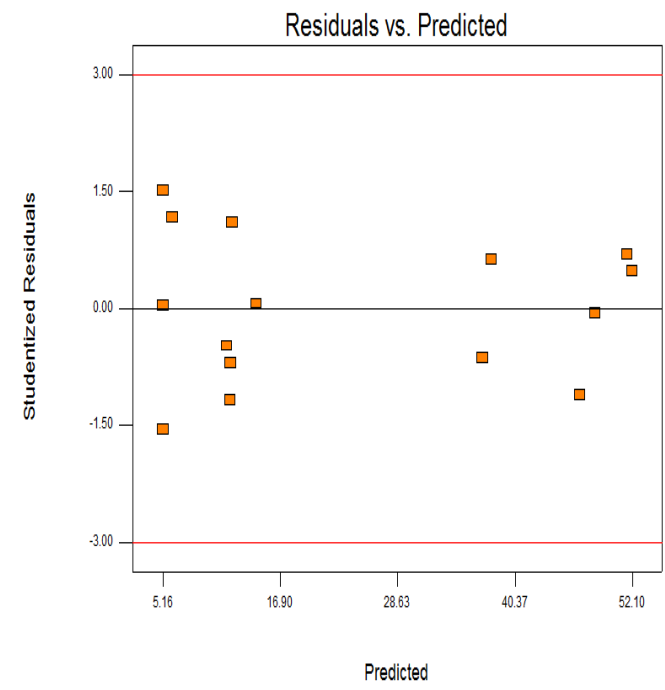

(b)

Figure 1: (a) The studentized residuals versus normal probability plot of betacyanin extracted dyeing of spun silk, (b) Residuals versus predicted plot of betacyanin extract dyeing of spun

\section{Interaction of Process Variables}

The effect of $\mathrm{pH}$, dye-bath concentration and dyeing time process variables on dyeing uptake percentage was further analyzed with the assistance of three-dimensional response surface plots in the views of the quadratic model. The effect of dyeing time and dye-bath concentration, illustrated in Figure 2, demonstrated that the dye uptake percentage decreased when dye-bath concentration changed from $75 \mathrm{~g} / \mathrm{L}$ to $85 \mathrm{~g} / \mathrm{L}$ and as dyeing time increased from $55 \mathrm{~min}$ to $65 \mathrm{~min}$. The findings of this study show that the maximum dye uptake percentage of $57.63 \%$ can be obtained when dyeing time and initial dye bath concentration was $65 \mathrm{~min}$ and $75 \mathrm{~g} / \mathrm{L}$ respectively. From this result, it is suggested that the percentage of dye uptake is likely depending on the initial of dye-bath concentration. As reported by Saleh et al., (2013), the effect of the initial dye-bath concentration relies on two factors which are the direct interaction between the free particle of color in the dye-bath solution and also the availability of active-sites on the yarn surface (Saleh et al., 2013). At lower dye-bath concentration, the ratio between the dye particle and fiber sites is higher which resulted the higher dye uptake as all the dye particles are attached to the active site on the yarn surface. Meanwhile, the higher concentrations resulted lower dyeuptake percentage may be due to the saturation of adsorption sites and the abundance of free molecule dye that unoccupied (Jaikumar, 2007). Similar trends were also reported by Liu et al., (2013) who studied the adsorption properties of natural dye lac dye onto the chitosan fiber (Liu et al., 2013). The surface plot of the interaction between $\mathrm{pH}$ and dyeing time at fixed initial dye-bath concentration $(80 \mathrm{~g} / \mathrm{L})$ is illustrated in Figure 3.

As the time increasing, the dye uptake percentage also increased from $49.89 \%$ to $58.30 \%$ 
at the same value of $\mathrm{pH} 2$. However, the dye uptake percentage was decreased drastically at about $24.2 \%$ from $58.30 \%$ to $34.17 \%$ when the $\mathrm{pH}$ value was changed from $\mathrm{pH} 2$ to $\mathrm{pH}$ 3. It is clearly shown that $\mathrm{pH}$ significantly gives effects to the dye uptake percentage. It is suggested that the changes of dye uptake percentages may due to the relationship between dye structures; the type of fiber used and dye stability. Guesmi et al. (2012) reported that the betacyanin's charge in the aqueous solution depends on the $\mathrm{pH}$ value. The betacyanin molecule may be present in cationized or monoanionic form under the intense acidic environment (Guesmi et al., 2012). Since the betacyanin dye encloses carboxyl group, it may interact ionically with the protonated terminal amino groups of spun silk fibers at acidic $\mathrm{pH}$ via ionic interaction. The anion of the dye has a complex character, and when it interacts with the fiber, the ionic force takes place. The dyeability of the dye molecule to the yarn surface was depends to this ionic attraction (Guesmi et al., 2013).

The 3D surface plot of the interaction between $\mathrm{pH}$ and dye-bath concentration, at a constant time of dyeing is presented in Figure 4. When the concentration of dye-bath is $75 \mathrm{~g} / \mathrm{L}$ and the $\mathrm{pH}$ of 2 , the dye-uptake percentage pointed the highest percentage of $57.63 \%$. The dye uptake percentage decreased from $57.63 \%$ to $46.84 \%$ with the increase of initial dye-bath concentration from $75 \mathrm{~g} / \mathrm{L}$ to $85 \mathrm{~g} / \mathrm{L}$ at the $\mathrm{pH}$ of 2 . This result indicates that the dyeing mechanism between betacyanin pigment with the spun silk is more likely to be affected by the changes of dye molecule structure in different $\mathrm{pH}$ conditions. It can be concluded that the dyeing process is influencing by the interaction between the dye molecule and the active-site of yarn surface. So, it is indicated that the dye attached to the yarn surface is preferably of chemical adsorption or chemisorption (Miyake et al., 2013) Chemisorption is a stronger perturbation of molecular structure with the formation of chemical bonds with the substrates. The connection between dye molecule and the active site of yarn is either covalent, ionic or metallic bonding (Yagub et al., 2014).

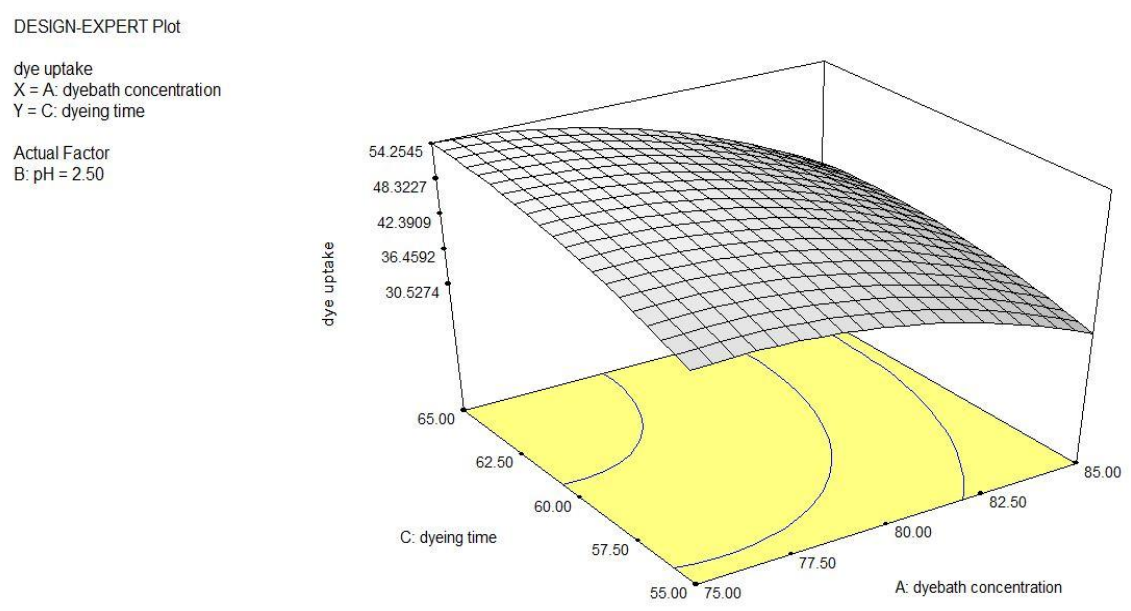

Figure 2: The effect of dyeing time and dye-bath concentration on the dye uptake percentage at a fixed $\mathrm{pH}$ of 2.5 

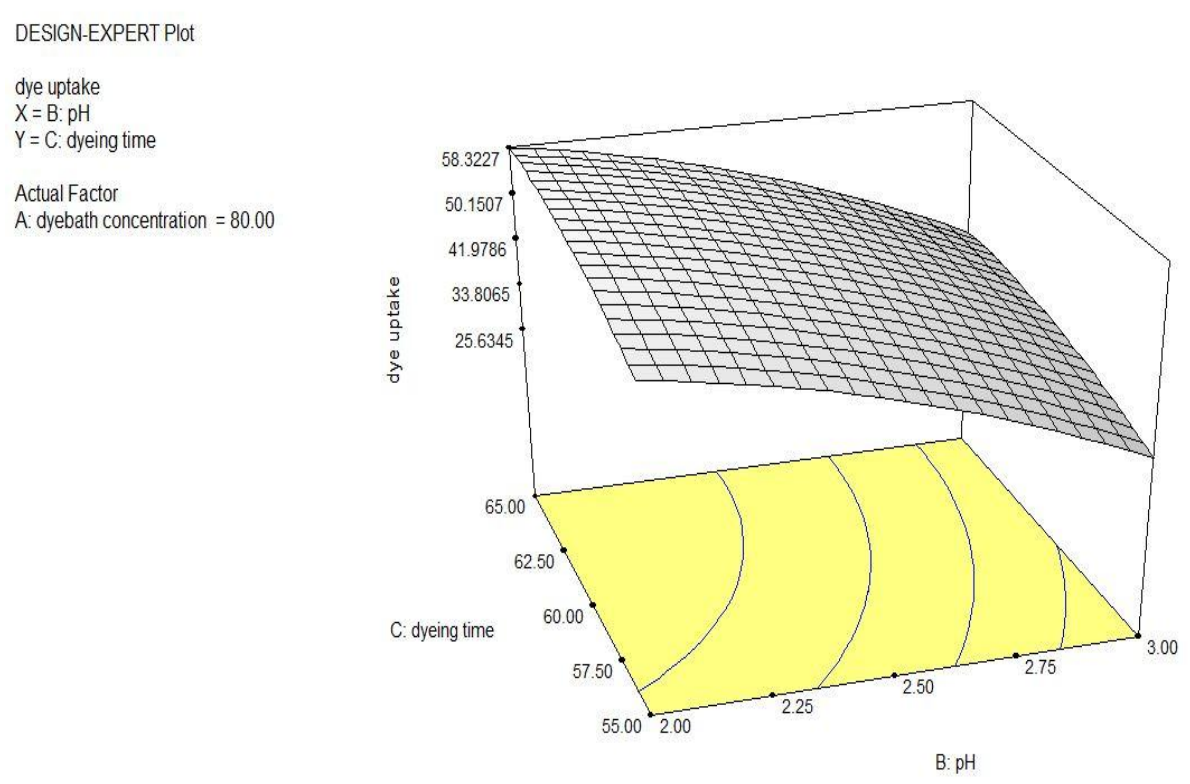

Figure 3: The effect of dyeing time and $\mathrm{pH}$ on the dye uptake percentage at a fixed dyebath concentration of $80 \mathrm{~g} / \mathrm{L}$
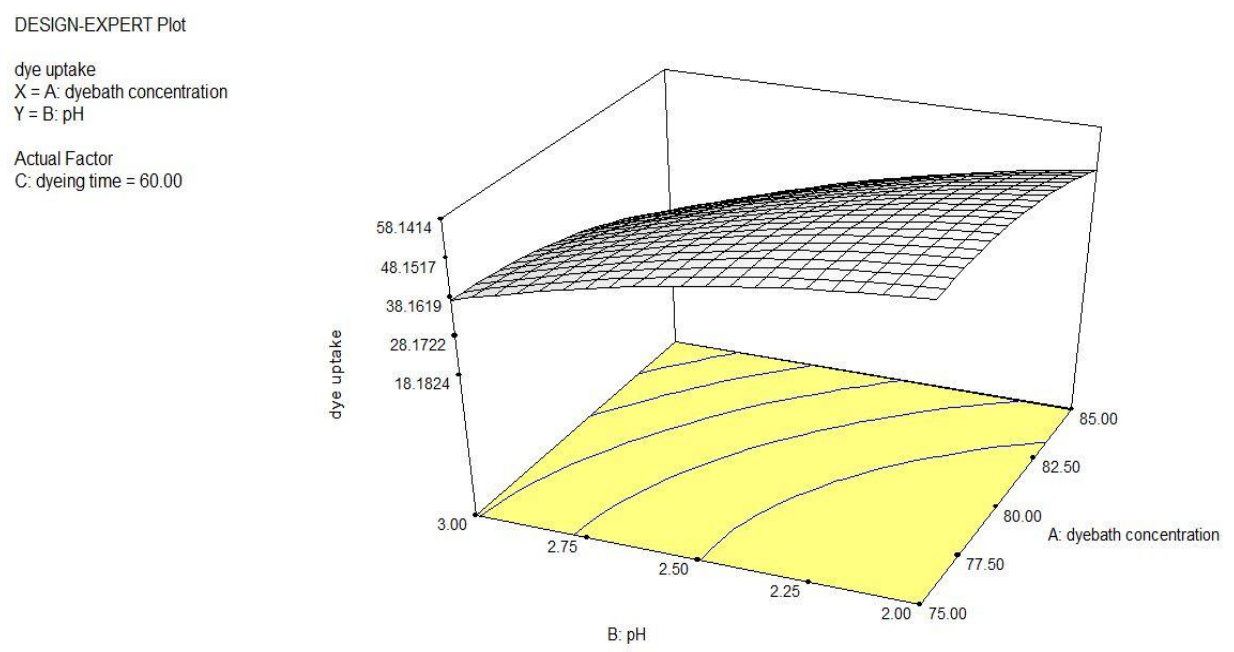

Figure 4: The effect of $\mathrm{pH}$ and dye-bath concentration on the dye uptake percentage at a fixed dyeing time of $60 \mathrm{~min}$

\section{Verification of Optimized Conditions and Predictive Model}

The experimental of verification or validation is crucial to be carried out to affirm the validity of the generated empirical model (Karthikeyan et al., 2010). Consequently, the analysis for approval was done to compare the estimated values of responses with the experimental data. The acquired actual values and their related predicted values from the selected experiments were compared. The residuals and percentage errors between the actual and predicted values of both responses over a selected range of operating levels are listed in Table 3. From Table 3, the result showed that the calculated percentage error is between $1.7 \%$ to $4.35 \%$. It could be deduced that the developed empirical model is 
substantially precise for a response, as the percentage error between the actual and predicted values was within the limit of 5\% (Zularism et al., 2009). It implies that the model is satisfactory at $95 \%$ of prediction interval, thus, it is adequate to approach the operational process for optimal dyeing uptake according to this model.

Table 3: Results of operating conditions with experimental design in confirmation runs

\begin{tabular}{ccccc}
\hline \multirow{2}{*}{ Run } & \multicolumn{2}{c}{ Factor } & $\begin{array}{c}\text { Dye uptake } \\
\text { percentage }\end{array}$ \\
\cline { 2 - 5 } $\mathbf{1}$ & $X_{1}$ (minutes) & $X_{2}(\mathrm{~g} / \mathrm{L})$ & $X_{3}(\mathrm{pH})$ & Error \% \\
$\mathbf{2}$ & 110 & 95 & 2 & 3.39 \\
$\mathbf{3}$ & 90 & 95 & 2 & 1.7 \\
$\mathbf{4}$ & 120 & 90 & 3 & 1.8 \\
$\mathbf{5}$ & 110 & 85 & 2 & 2.245 \\
\hline
\end{tabular}

In the view of prior examination, the significant factors which are dyeing time, dye concentration and $\mathrm{pH}$ were dominant for the response of dyeing uptake percentage. The prediction of response at $95.0 \%$ prediction interval is possible by employing the optimization mode capability of the software. The optimization procedure has been executed for the dyeing condition of betacyanin extracted onto the spun silk yarn and prediction was set within the defined level. The results from the model were determined to be as: dyeing time $=95 \mathrm{~min}$ ), dye concentration $=110 \mathrm{~g} / \mathrm{L}$ and $\mathrm{pH}=2$. The maximum value of dyeing uptake percentage was $51.58 \%$ under the suggested condition that generated from the model. In order to validate the predicted optimized conditions, the experimental confirmation run was executed by using the proposed model conditions. The result of the dyeing uptake percentage calculated from the experimental run was $52.45 \%$. The error percentage between the predicted and actual value is within $5 \%$ as it can be confirmed that the projected mathematical models are practically consistent and precise.

\subsection{CONCLUSIONS}

As the conclusion, the optimum conditions for the dyeing uptake of betacyanin pigment extracted onto the spun silk yarn can be reliably employed by using the central composite design under response surface methodology. Analysis of variance showed a high coefficient of determination value $\left(R^{2}\right)$ of 0.9986 for dyeing uptake exhaustion percentage. It indicated that the experimental data is adequately fit with the second-order polynomial regression model. The optimum conditions for dyeing process are as follows: dyeing time $=95$ minutes, dye-bath concentration $=110 \mathrm{~g} / \mathrm{L}$ and $\mathrm{pH} 2$. By using the optimum conditions, the dyeing uptake percentage was found to be $52.45 \%$. The percentage errors for experimental validation showed a minimal difference which is $1.68 \%$. Hence, the generated model using CCD in this study is considered to be a valid optimization. 


\section{ACKNOWLEDGEMENT}

Financial support from Universiti Malaysia Pahang (GRS130316) is gratefully acknowledged and also scholarship from Ministry of Education Malaysia (MyPHD).

\section{REFERENCES}

Chairat, M., Rattanaphani, S., Bremner, J. B., \& Rattanaphani, V. (2008). Adsorption kinetic study of lac dyeing on cotton. Dyes and Pigments, 76(2), 435-439.

Demirel, M., \& Kayan, B. (2012). Application of response surface methodology and central composite design for the optimization of textile dye degradation by wet air oxidation. International Journal of Industrial Chemistry, 3(1), 24.

Erkan, G., Şengül, K., \& Kaya, S. (2011). Dyeing of white and indigo dyed cotton fabrics with Mimosa tenuiflora extract. Journal of Saudi Chemical Society, 6(1), 1-10.

Guesmi, A., Hamadi, N. Ben, Ladhari, N., \& Sakli, F. (2012). Dyeing properties and colour fastness of wool dyed with indicaxanthin natural dye. Industrial Crops and Products, 37(1), 493-499.

Guesmi, a., Ben hamadi, N., Ladhari, N., \& Sakli, F. (2013). Sonicator dyeing of modified acrylic fabrics with indicaxanthin natural dye. Industrial Crops and Products, 42, 63-69.

Guesmi, a., Hamadi, N. Ben, Ladhari, N., Saidi, F., Maaref, H., \& Sakli, F. (2013). Spectral characterization of wool fabric dyed with indicaxanthin natural dye: Study of the fluorescence property. Industrial Crops and Products, 46, 264-267.

Guesmi, a., Ladhari, N., Hamadi, N. Ben, \& Sakli, F. (2012). Isolation, identification and dyeing studies of betanin on modified acrylic fabrics. Industrial Crops and Products, 37(1), 342-346.

Jaikumar, V. (2007). Effect of Biosorption Parameters Kinetics Isotherm and Thermodynamics for Acid Green Dye Biosorption from Aqueous Solution by Brewery Waste. International JOurnal of Chemistry, 1(1), 2-12.

Karthikeyan, K., Nanthakumar, K., Shanthi, K., \& Lakshmanaperumalsamy, P. (2010). Response surface methodology for optimization of culture conditions for dye decolorization by a fungus, Aspergillus niger HM11 isolated from dye affected soil. Iranian Journal of Microbiology, 2(4), 213-22.

Kunnika, S., \& Pranee, A. (2011). Influence of enzyme treatment on bioactive compounds and colour stability of betacyanin in flesh and peel of red dragon fruit Hylocereus polyrhizus (Weber) Britton and Rose. International Food Research Journal, 18(4), 1437-1448.

Liu, L., Zhang, J., \& Tang, R. C. (2013). Adsorption and functional properties of natural lac dye on chitosan fiber. Reactive and Functional Polymers, 73(11), 1559-1566.

Miyake, Y., Ishida, H., Tanaka, S., \& Kolev, S. D. (2013). Theoretical analysis of the pseudo-second order kinetic model of adsorption. Application to the adsorption of $\mathrm{Ag}(\mathrm{I})$ to mesoporous silica microspheres functionalized with thiol groups. Chemical Engineering Journal, 218, 350-357.

Nasirizadeh, N., Dehghanizadeh, H., Yazdanshenas, M. E., Moghadam, M. R., \& Karimi, A. (2012). Optimization of wool dyeing with rutin as natural dye by central composite design method. Industrial Crops and Products, 40, 361-366.

Ojha, K., \& Achwal, V. (2014). Enhancement in Fabric Quality by Optimizing the Dyeing Process Parameters Using Response Surface Methodology. IOSR Journal of 
Mechanical and Civil Engineering, 11(3), 70-76.

Prakash Maran, J., \& Manikandan, S. (2012). Response surface modeling and optimization of process parameters for aqueous extraction of pigments from prickly pear (Opuntia ficus-indica) fruit. Dyes and Pigments, 95(3), 465-472.

Saleh, M. S., A, A. E. Y., \& El-badry, K. (2013). Dyeing of Cationized Cotton Fabrics with Natural Dye Extracted from Acacia. International Journal of Textile Science, 2(2), 30-35.

Sinha, K., Saha, P. Das, \& Datta, S. (2012). Extraction of natural dye from petals of Flame of forest (Butea monosperma) flower: Process optimization using response surface methodology (RSM). Dyes and Pigments, 94(2), 212-216.

Stintzing, F. C., Schieber, A., \& Carle, R. (2002). Betacyanins in fruits from red-purple pitaya, Hylocereus polyrhizus (Weber) Britton \& Rose. Food Chemistry, 77(1), 101-106.

Subroto, E., Manurung, R., Jan, H., \& Augustinus, A. (2015). Optimization of mechanical oil extraction from Jatropha curcas L . kernel using response surface method. Industrial Crops \& Products, 63, 294-302.

Tang, C. S., \& Norziah, M. H. (2007). Stability of betacyanin pigments from red purple pitaya fruit (Hylocereus polyrhizus): Influence of $\mathrm{pH}$, temperature, metal ions and ascorbic acid. Indonesian Journal of Chemistry, 7(3), 327-331.

Yagub, M. T., Sen, T. K., Afroze, S., \& Ang, H. M. (2014). Dye and its removal from aqueous solution by adsorption: A review. Advances in Colloid and Interface Science, 209(April), 172-184.

Zainoldin, K.H., Baba, a. S. (2009). The Effect of Hylocereus polyrhizus and Hylocereus undatus on Physicochemical, Proteolysis, and Antioxidant Activity in Yogurt. Engineering and Technology, 60(12), 361-366.

Zularisam, a. W., Ismail, a. F., Salim, M. R., Sakinah, M., \& Matsuura, T. (2009). Application of coagulation-ultrafiltration hybrid process for drinking water treatment: Optimization of operating conditions using experimental design. Separation and Purification Technology, 65(2), 193-210. 